\title{
Lipopolysaccharide in cells infected by Chlamydia trachomatis
}

\author{
S. Campbell, ${ }^{1}$ S. J. Richmond, ${ }^{2}$ P. S. Yates $^{2}$ and C. C. Storey ${ }^{2}$ \\ Author for correspondence: S. Campbell. Tel: +44 61447 3814. Fax: +44614451186.
}

\footnotetext{
1 Department of Obstetrics and Gynaecology, University Hospital of South Manchester, Nell Lane, West Didsbury, Manchester M20 8LR, UK

2 Department of Pathological Sciences, Stopford Building, University of Manchester, Oxford Road, Manchester M13 9PT, UK
}

\begin{abstract}
In view of the controversy concerning the expression of chlamydial lipopolysaccharide (LPS) in the eukaryotic host cell, the presence of this molecule was examined in three cell types which were experimentally infected with Chlamydia trachomatis serotype E. LPS was detected in the McCoy cell line, human endometrial epithelium and human amniotic epithelium with two monoclonal antibodies. The appearance and distribution of LPS at the host cell surface during the chlamydial developmental cycle and its transmission to neighbouring cells were examined by immunofluorescence microscopy after air drying of the host cells. LPS distribution was not uniform; it was first observed on regions of the cell surface in close proximity to the chlamydial endosome (inclusion). Soon after, the antigen was also detected at points of contact with neighbouring uninfected cells. Immunofluorescent plaques of host cells contaminated with LPS were thus formed in the vicinity of infected cells. These plaques increased in size over $\mathbf{2} \mathrm{d}$ before becoming smaller as host cell lysis occurred. The major outer-membrane protein (MOMP) was not visualized on the host cell surface after air drying. No cell-surface LPS antigen was observed in live cells or those fixed in formaldehyde without air drying. Conventional methanol fixation and immunolocalization of LPS and MOMP in parallel infected cultures stained these antigens within inclusions in the expected fashion. Radio-immunoassays were used to quantify LPS in confluent McCoy cell monolayers during the chlamydial developmental cycle. Cellsurface-associated and inclusion-associated LPS, measured by direct binding of 125|-labelled anti-LPS monoclonal antibodies to air-dried or methanol-fixed monolayers respectively, increased for up to $3 \mathrm{~d}$ then declined. Cell-surfaceassociated LPS is not directly accessible to antibodies in the hydrated cell. This apparent masking of the antigen may have a significant advantage for persistence of the parasite in vivo, since such host-cell-associated antigen is unlikely to be a target for immune attack.
\end{abstract}

Keywords: Chlamydia trachomatis, lipopolysaccharide, cell surface, epithelium

\section{INTRODUCTION}

Chlamydiae are Gram-negative bacteria which cause persistent intracytoplasmic infection of eukaryotic cells. Their unique developmental cycle takes place in the host cell cytoplasm within an expanding fluid-filled endosome, or inclusion, where the replicating organisms are protected from direct attack by the host immune system. However, it is not clear whether the intact infected host

Abbreviations: FITC, fluorescein isothiocyanate; MOMP, major outermembrane protein; PBS, Dulbecco's phosphate-buffered saline without divalent cations; PBS-M, PBS supplemented with $5 \%(w / v)$ dried milk powder. cell provides a target for attack by the immune system before lysis. Despite experimental data showing that chlamydiae can evoke cell-mediated immunological responses (Igietseme \& Rank, 1991), at present there is no conclusive evidence that chlamydia-infected cells express antigens at their surface in a form which makes them susceptible to cytotoxic T-cell attack (Morrison, 1990).

Chlamydial antigens are, however, not restricted to the inclusion during the course of the intracellular developmental cycle. A chance discovery showed that antigens could be demonstrated by immunofluorescence at the surface of infected McCoy cells if the cultures were air dried and alcohol extraction was avoided (Richmond, 
1980). This phenomenon was first demonstrated with polyclonal antisera which contained complement-fixing antibodies to chlamydiae and which reacted with both Cblamydia psittaci and Chlamydia trachomatis. These observations suggested that the antigen involved was the genus-specific lipopolysaccharide (LPS) (Dhir et al., 1971). More recent experiments with monoclonal antibodies have confirmed that LPS is indeed present at the surface of air-dried infected cells (Karimi et al., 1989).

Ultrastructural examination of the dried cells demonstrated that the host cell cytoplasm is remarkably well preserved and the chlamydial inclusion still intact after the process of air drying (Richmond \& Stirling, 1981.). Appearance of LPS at the cell surface therefore does not appear to be an artifact caused by disruption of the inclusion or individual chlamydiae. Nevertheless others, using fixation and processing methods which would seem more appropriate to in situ hybridization than to immunofluorescence, have suggested that the localization of LPS antigens at the host cell surface may be an artifact (Baumann et al., 1992).

The present work extends our earlier observations on genus antigen at the surface of chlamydia-infected host cells. We confirm that this antigen is chlamydial LPS (Karimi et al., 1989), demonstrate that it becomes associated with the surface of infected human epithelial cells as well as the McCoy cell line, and show that it spreads over the infected cell surface to that of adjacent cells. These results emphasize the fact that the surfaces of both infected host cells and those of neighbouring uninfected cells are antigenically modified by LPS during the course of chlamydial infection. However, this antigen is masked in the living hydrated cell and is therefore probably not a target for host immune attack in vivo.

\section{METHODS}

Eukaryotic host cell culture. Three cell types were used in this study, the McCoy cell line (Flow Laboratories), human endometrial epithelium and human amniotic epithelium. Both types of human epithelium were obtained and cultured by methods previously described (Campbell et al., 1988; Aplin et al., 1985) using tissue obtained with the permission of the local ethics committee. Briefly, human endometrial currettings were digested in a mixture of collagenase $1 \mathrm{mg} \mathrm{m}^{-1}$ (Sigma) and hyaluronidase $1 \mathrm{mg} \mathrm{ml}^{-1}$ (Sigma) and glandular fragments were isolated by filtration. The isolated gland fragments were plated onto glass coverslips coated with rat-tail tendon collagen (Campbell et al., 1988). Epithelial cells migrated from the glandular fragments to form large islands. Human amniotic epithelial cells, obtained from a placenta at gestational term by digesting the amnion with $0.25 \%(\mathrm{w} / \mathrm{v})$ trypsin, $(0 \cdot 1 \%)$ EDT A, were cultured on collagen-coated glass. All cells were grown on $10 \mathrm{~mm}$ diameter coverslips in flat-bottomed plastic screw-top tubes in a 1:1 mixture of DME:Ham's F12 growth medium (Sigma) supplemented with $15 \mathrm{mM}$ HEPES, $10 \%(\mathrm{v} / \mathrm{v})$ foetal bovine serum, $2 \mathrm{mM}$ glutamine and $100 \mu \mathrm{g}$ streptomycin ml ${ }^{-1}$ or $100 \mathrm{ng}$ kanamycin $\mathrm{ml}^{-1}$.

Chlamydial culture and infection. A genital isolate, T181, of $C$. trachomatis serotype E (Sompolinsky \& Richmond, 1974) was passaged in McCoy cells without the use of cycloheximide, and infected cell homogenates were stored in a cryoprotectant solution containing $10 \%(\mathrm{w} / \mathrm{v})$ sorbitol and $25 \%$ foetal bovine serum. The infectivity of such homogenates was determined by titration in McCoy cell monolayers. Appropriate dilutions of homogenates or filter-purified chlamydiae prepared from them (Campbell et al., 1991) were used to infect the three cells types used in this study. Infection was initiated by centrifuging the chlamydial inoculum on to the monolayer at $2000 \mathrm{~g}$ for $30 \mathrm{~min}$ at $35^{\circ} \mathrm{C}$. No cycloheximide was included in the culture medium.

Antibody characterization. Two anti-LPS antibodies were used in this study. Monoclonal antibody J12 (Thornley et al., 1985) was supplied by Boots-Celltech. The other, designated $512 \mathrm{~F}$, was locally produced by immunization of mice with $C$. trachomatis serotype L2 strain 434 (Wang \& Grayston, 1971). Earlier work not repeated here showed that antibody $512 \mathrm{~F}$ is reactive in enzyme immune assays with a periodate-sensitive antigen present in whole chlamydiae (S. J. Richmond, unpublished observations). In this work the specificity of antibody $512 \mathrm{~F}$ was compared to that of $\mathrm{J} 12$ by Western blotting with purified chlamydiae (Howard et al., 1974). Chlamydiae were solubilized by boiling in sample buffer containing $0.05 \mathrm{M}$ Tris/HCl, $\mathrm{pH} 6 \cdot 8,0 \cdot 1 \mathrm{M}$ dithiothreitol, $2 \%(\mathrm{w} / \mathrm{v})$ SDS, $10 \%$ (v/v) glycerol and $0 \cdot 1 \%$ bromophenol blue. The chlamydial components were separated in parallel with molecular mass standards (Amersham) by discontinuous SDS-PAGE on 12.5\% $(\mathrm{w} / \mathrm{v})$ gels and then electroblotted onto $0.45 \mu \mathrm{m}$ pore size nitrocellulose. The membranes were blocked for $60 \mathrm{~min}$ in Dulbecco's phosphate-buffered saline without divalent cations (PBS) supplemented with $5 \%(\mathrm{w} / \mathrm{v})$ skimmed milk powder (PBS-M), incubated with a $1 / 2$ dilution of the primary antibodies in PBS-M overnight at $4{ }^{\circ} \mathrm{C}$, washed three times in PBS and then incubated in a $1 / 800$ dilution of swine anti-mouse immunoglobulin peroxidase conjugate (Dako) for $4 \mathrm{~h}$ at room temperature. After three further washes in PBS, the immunoreactive components were visualized by incubation of the membrane in $12 \mathrm{mM}$ acetic acid, $37.5 \mathrm{mM}$ sodium acetate, 0.05 vol. hydrogen peroxide, $0.02 \% 3$-amino-9-ethylcarbazole (dissolved in $5 \%, \mathrm{v} / \mathrm{v}$, dimethylformamide) for 1-2 min at room temperature. In order to verify that bands present on Western blots were correctly identified, approximately $10^{11}$ chlamydiae (strain L2/434) were isolated on $32-50 \%$ renographin gradients (Howard et al., 1974). The LPS was then purified by solvent extraction using the phenol/chloroform/ light petroleum method (Galanos et al., 1969), electrophoresed in $15 \%$ acrylamide gels, electroblotted as before, and then incubated with $2 \times 10^{6}$ c.p.m. ${ }^{125} \mathrm{I}$-labelled antibody (J12). Both antibodies were also tested by immuno-dot blot (Storey et al., 1987) against the same batch of purified LPS and crude homogenates of infected McCoy cells.

The immunoreactivity of antibody $512 \mathrm{~F}$ against different chlamydial isolates was tested by indirect immunofluorescence against methanol-fixed McCoy cells infected for $48 \mathrm{~h}$ using the following: two isolates of C. trachomatis [L2/434 (Wang \& Grayston, 1971) and E/T181 (Sompolinsky \& Richmond, 1974)]; 20 isolates of $C$. psittaci from a variety of hosts [duck N352, N232 N215b, 2020 and 360 (Richmond et al., 1982; Bacon et al., 1986); parakeet - 6BC (Morgan \& Wiseman, 1946); feral pigeon - 1196 and 1121; wood pigeon - 741; collared dove 1021; partridge - $\operatorname{Par}^{1}$ (Richmond et al., 1990); black-headed gull - Ral/56 (Strauss et al., 1957); Cal 10 (Francis \& Magill, 1938); guinea pig - GPIC (Murray, 1964); cat - Fpn/pring (Wills et al., 1984); sheep - EAE/LX (Dr J. M. Wills); koala H3, BE, DP and MB (G. Mearns, Cell Labs PTY Ltd, Brookvale, Australia)]; and two isolates of C. pneumoniae [human-IOL207 (Dwyer et al., 1972); and horse - N16 (Storey et al., 1993)].

Immunofluorescence microscopy. LPS within the inclusions of cells infected with the T181 C. trachomatis isolate was visualized 


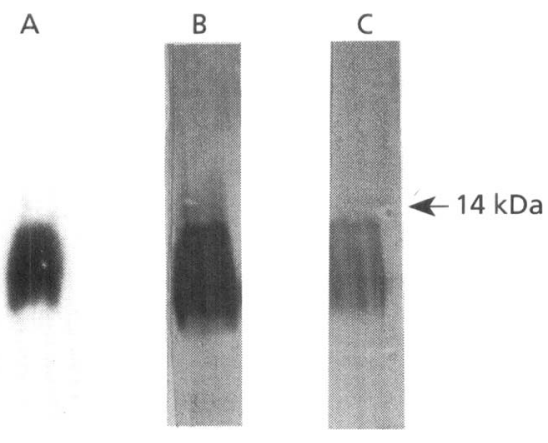

Fig. 1. Lane $A$ is an autoradiograph of ${ }^{125}$-labelled antibody $\mathrm{J} 12$ used in a Western blot of purified LPS. Lanes B and C are Western blots of purified chlamydiae showing the reactivity of monoclonal antibody $J 12$ and $512 \mathrm{~F}$ respectively. Both antibodies react with a low-molecular-mass chlamydial antigen with the same electrophoretic mobility as purified LPS.

after conventional methanol fixation by immunofluorescence microscopy using either monoclonal antibody. After an initial $45 \mathrm{~min}$ incubation in anti-LPS antibody the cultures were washed with PBS and incubated with sheep anti-mouse immunoglobulin conjugated to FITC. The coverslips were mounted in non-fade mountant and examined with oil-immersion phase lenses. The major outer-membrane protein (MOMP) was visualized by direct immunofluorescence with an FITCconjugated monoclonal antibody containing a red counterstain (Syva).

It was necessary to dry infected cells in order to demonstrate surface-associated LPS (Richmond \& Stirling, 1981). Infected cells were fixed in $4 \%(\mathrm{v} / \mathrm{v})$ formaldehyde in PBS for at least $20 \mathrm{~min}$ at room temperature then washed extensively with PBS to remove any soluble LPS (six washes with $5 \mathrm{ml}$ ). The salt solution was removed before drying by washing the cultures quickly with distilled water. The coverslips were immediately drained of surface water by touching them against a paper towel and air dried for at least $2 \mathrm{~h}$ at $37^{\circ} \mathrm{C}$ then stained for LPS as above. In two experiments McCoy cells were air dried from water without prior formaldehyde fixation and stained for LPS. The unfixed cells gave almost indistinguishable results and so demonstrated that the immunofluorescence staining was not an artifact of formaldehyde fixation. In a control experiment airdried McCoy cells were stained for MOMP rather than LPS.

Live unfixed cells were used in two experiments to determine whether anti-LPS antibodies bound to the unmodified host cell surface. Live infected McCoy cell monolayers in culture tubes were placed on ice, to minimize internalization of antibody. They were incubated with anti-LPS antibody for $2 \mathrm{~h}$, then fixed with formaldehyde for $20 \mathrm{~min}$ at room temperature, washed again with PBS, then incubated with the fluorescent conjugate.

Detection of LPS by radio-labelled monoclonal antibodies. Both monoclonal antibodies were labelled with ${ }^{125} \mathrm{I}$ (Storey et al., 1987). Cultures were fixed with formaldehyde at room temperature and air dried, then washed with PBS before radiolabelled antibody was added. Antibody with 50000 c.p.m. of ${ }^{125} \mathrm{I}$ label was added to each culture tube followed by incubation overnight at room temperature. Unbound antibody was removed by washing six times with $5 \mathrm{ml}$ PBS. The bound antibody was then measured by placing the tubes directly in the gamma counter. Comparative binding to inclusions was measured in parallel cultures which had been fixed in methanol but not air dried.

\section{RESULTS}

Both monoclonal antibodies used in this study reacted in Western blots of whole chlamydiae with a diffuse band which migrated ahead of the $14.4 \mathrm{kDa}$ molecular mass
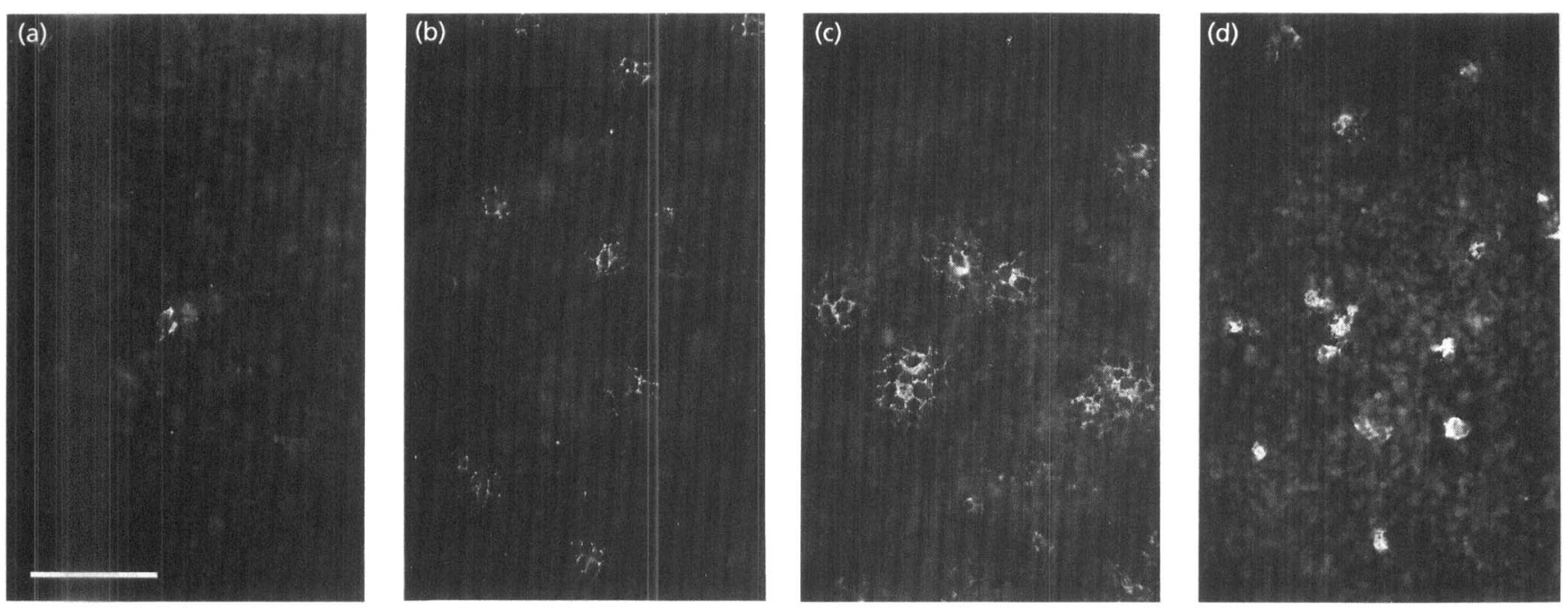

Fig. 2. Confluent McCoy cells were infected with a homogenate of chlamydia-infected McCoy cells, then fixed with formaldehyde and air dried at various times throughout the developmental cycle. The antigen was visualized with antibody 512F. Four time points are illustrated at low magnification: (a) $6 \mathrm{~h}$; small patches of fluorescence can be observed because homogenates rather than filter-purified chlamydiae were used as inocula; (b) $20 \mathrm{~h}$; discrete fluorescent plaques were now detectable; (c) $48 \mathrm{~h}$; the plaques have increased in size because LPS has spread to more neighbouring cells; (d) $72 \mathrm{~h}$; cell lysis has begun and the plaque size has greatly decreased. Bar, $100 \mu \mathrm{m}$. 



Fig. 3. Human amniotic epithelial cells were infected for $48 \mathrm{~h}$. Immunolocalization was carried out with antibody $512 \mathrm{~F}$ and examined at high magnification. (a) The cells were formaldehyde fixed before air drying. The central brightstaining area shows one cell and the point of contact with two adjoining neighbours (arrows). A chlamydial inclusion was observed by phase microscopy in the central brightly stained cell. The fluorescence is most intense in the area directly over the inclusion but is much weaker in the thin lamellipodial region (at the bottom of the picture) and on the cellular process, over which the staining intensity gradually declines. Two adjacent cells (arrows) also have surface-associated antigen, but only near the point of contact with the infected cell. (b) After air drying without formaldehyde fixation, similar patterns of staining can be observed. The central portion of the cell is out of the focal plane. The surface of the cell is vesiculated (arrows) in a way which is thought to be an artifact of the drying process. Bar, $15 \mu \mathrm{m}$.

marker (Fig. 1). This was identical to the band identified on Western blots of purified LPS by ${ }^{125}$ I-labelled antibody
J12. Both antibodies also reacted in dot blots with either purified LPS or proteinase $\mathrm{K}$ treated homogenates of infected cells (data not shown). The locally produced antibody, $512 \mathrm{~F}$, was additionally shown to stain the inclusions of two isolates of $C$. trachomatis, two isolates of C. pneumoniae, and 20 isolates of $C$. psittaci by indirect immunofluorescence of infected McCoy cells. The epitopes identified by this monoclonal antibody are therefore probably common to all chlamydiae. No attempt was made to test antibody reactivity with glycolipids produced in infected cells (Stuart et al., 1991).

Immunofluorescence microscopy after conventional fixation in methanol, or formaldehyde followed by methanol, resulted in the normal pattern of inclusion staining with both antibodies.

Air drying of the cultures revealed cell-surface-associated LPS by indirect immunofluorescence in McCoy cells (Fig. 2), human endometrial epithelium (Fig. 3) and human amniotic epithelium (Fig. 4). The pattern of staining produced by each LPS antibody was indistinguishable. No surface-associated LPS was observed on fixed cells which had not been dried, or on live McCoy cells. In confluent cultures the antigen was detected as fluorescent plaques which involved groups of host cells. Wellpreserved inclusions were visible in fixed air-dried cultures by phase microscopy and were always associated with the fluorescent plaques. In less than $5 \%$ of the plaques in McCoy cells infected for $48 \mathrm{~h}$ no inclusion was visible by phase microscopy. In a control experiment an anti-MOMP monoclonal antibody was used in place of LPS to determine whether another major chlamydial outer envelope component could be detected after air drying. No surface-associated MOMP was detected on infected cells or as plaques involving neighbouring cells. Individual chlamydiae were however visualized by MOMP immunofluorescence in a small proportion of infected cells which had been damaged during the process
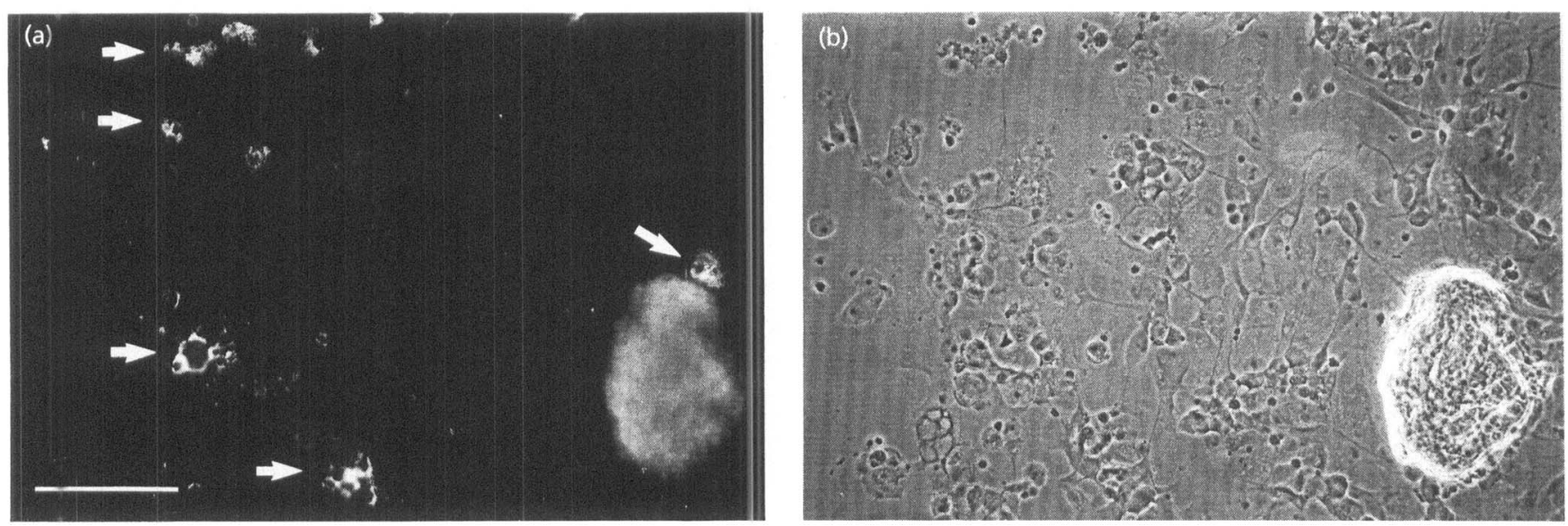

Fig. 4. Human endometrial epithelial cells after $48 \mathrm{~h}$ infection, fixed in formaldehyde, air dried and stained with antibody 512F. (a) A segment of an outgrowth from an endometrial gland fragment which shows plaques of antigen (arrows) that are mostly located toward the edge of the epithelial sheet. The apparent fluorescence of the tissue fragment (bottom right) is non-specific background staining due to its thickness. (b) A phase micrograph of the same field. Bar, $100 \mu \mathrm{m}$. 

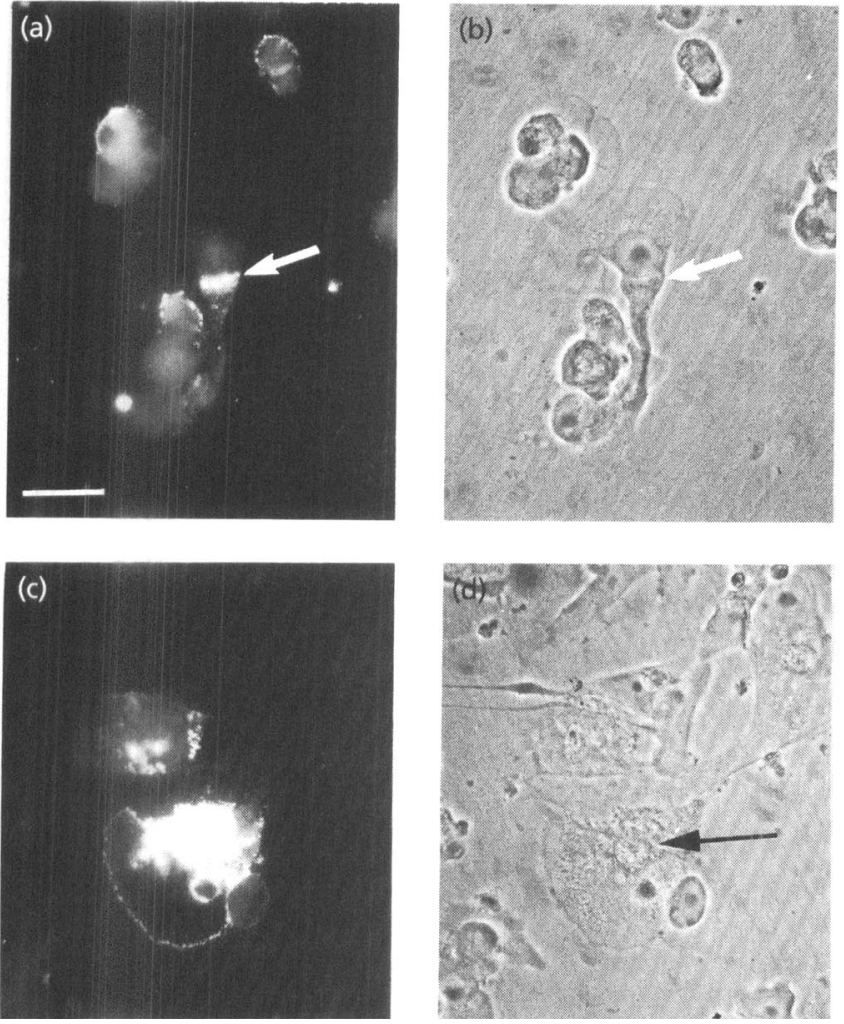

Fig. 5. Endometrial cells after $48 \mathrm{~h}$ infection fixed in formaldehyde, air dried and stained with antibody 512F. (a) One cell shows a very discrete band of staining over the perinuclear chlamydial inclusion (arrow). (b) Phase micrograph of the same field with the chlamydial inclusion indicated (arrow). (c) The large cell in the centre of the picture has an intense patch of staining over the inclusion and a thin particulate band of staining at the cell periphery. (d) Phase micrograph of the same field as (c) with the inclusion indicated (arrow). Bar, $25 \mu \mathrm{m}$.

of drying (coloured micrographs not shown). The damaged inclusions were distinguished by the fact that a hole (an unstained black area) in the cell and inclusion was always observed with the red counterstain and only a small number of chlamydiae remained within the inclusion. This small proportion of damaged inclusions (observed after MOMP staining) accounted for the fact that fluorescent plaques of LPS staining were sometimes observed where no inclusion could be detected by phase microscopy.

The development of LPS surface fluorescence over a $3 \mathrm{~d}$ period was studied in confluent monolayers of McCoy cells, which were examined immediately after centrifugal inoculation and at $6,20,22,30,48,56$ and $72 \mathrm{~h}$ in two separate experiments (Fig. 2). If crude homogenates of infected cells were used as the inoculating material very small patches of cell-surface fluorescence were observed immediately after centrifugation and $6 \mathrm{~h}$ later. This LPS was shown to be a contaminant of the homogenate since after inoculation with filter-purified elementary bodies no

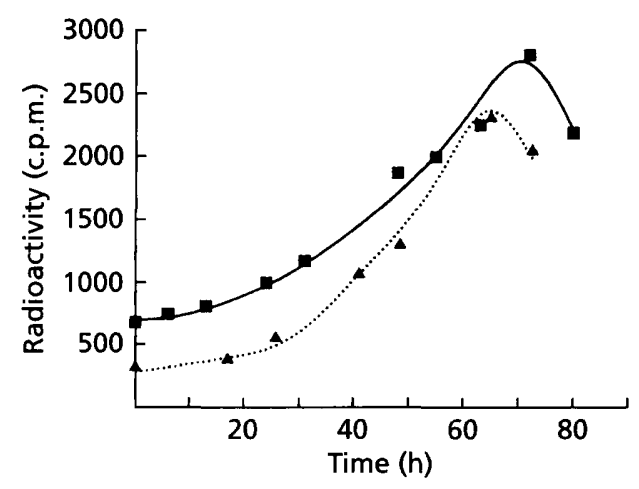

Fig. 6. The development of cell-surface-associated and inclusion-bound LPS was measured in air-dried ( $\boldsymbol{\Delta} \cdot \cdots \mathbf{\Delta})$ or methanol-fixed ( $-\boldsymbol{D}$ ) McCoy monolayers with ${ }^{125}$-labelled antibody J12. After an initial slow increase in LPS detection during the first day, LPS content increased more rapidly for another $2 \mathrm{~d}$ before starting to decline on the fourth day of infection. It is important to realize that an absolute comparison of the amount of antibody bound after the two treatments cannot be made, as methanol extracted LPS at the cell surface and possibly at other intracellular sites as well. Each data point represents the mean of two replicate cultures.

such patches were detected. The exact number of cells involved in each plaque was hard to determine because there were situations where it was difficult to decide whether LPS was merely at the boundary of one cell or also extending on to a closely apposed neighbour, but after 20 and $22 \mathrm{~h}$ a maximum of 6-10 cells were involved. By $30 \mathrm{~h}, 5-20$ fluorescent cells were seen in each plaque, and by $48 \mathrm{~h}$ the number had risen to 10-40. Plaques of widely varying size and shape were thus found at each time point within the same confluent monolayer. On the third day of infection the size of the plaques considerably diminished as host cell lysis ensued, which suggested a rapid turnover or shedding of antigen.

The distribution of plaques after $48 \mathrm{~h}$ in endometrial epithelial islands was similar to that previously reported for inclusions (Campbell et al., 1988). Plaques, like inclusions, tended to be situated towards the edge of the expanding epithelial sheets (Fig. 4). However, at $48 \mathrm{~h}$ fewer cells were involved in the plaques in endometrial cultures than in McCoy cell cultures, possibly because the epithelial cells were much larger in area than the McCoy cells.

Close examination of the fluorescent surface of all three host cell types with a high-magnification objective lens revealed a very unusual vesiculated surface (Fig. 3). This was probably a result of drying, as no evidence of these surface structures could be observed on hydrated cells. In each of the three cell types studied, distinctive patches of fluorescence were detected directly over the inclusion of intact cells during the second day of infection (Fig. 5a). The intensity of fluorescence declined, sometimes abruptly and sometimes more gradually, with increasing distance from the site of the inclusion (compare Fig. 3a and Fig. 5a). In isolated endometrial epithelial cells, staining was seen in dense patches over the inclusion and 
also around the periphery of the lamellipodia, which suggests that the chlamydial antigen had become redistributed during the process of cell locomotion and membrane turnover (Fig. 5c). When LPS was found on an uninfected neighbouring cell the fluorescence was most intense at the point of cell-to-cell contact and declined in intensity with increasing distance from that point (Fig. 3a).

The development of LPS on the McCoy cell surface over the first $3 \mathrm{~d}$ of infection was quantified by the binding of radio-labelled antibody and compared to the binding to inclusions after methanol fixation on a parallel series of cultures. Similar results were obtained with each monoclonal antibody. Both surface and inclusion LPS increased for almost $3 \mathrm{~d}$ then declined as infected cells lysed (Fig. 6). There was a lag of approximately $1 \mathrm{~d}$ before LPS could be detected on the surface by this procedure. The quantitative changes therefore corresponded to the initial increase and subsequent reduction in plaque size detected by immunofluorescence.

\section{DISCUSSION}

This work confirms that chlamydial LPS becomes associated with the host cell surface during the course of the chlamydial growth cycle. The appearance of this antigen in three infected cell types stained with anti-LPS morioclonal antibodies is similar to that visualized in earler work with McCoy cells and polyclonal antisera (Richmond \& Stirling, 1981). We are confident that this phenomenon is the same as that described by one other group, because of the similarity of fixation techniques and staining patterns with McCoy cells (Karimi et al., 1989). We also believe that it is not a fixation artifact (Baumann et al., 1992) but rather a normal concomitant of the chlamydial growth cycle. There are several reasons for this belief. There is a close parallel between plaque size and total surface antigen described here and growth of inclusions (Campbell et al., 1989) and infectivity of the cultures (Stirling \& Richmond, 1977). When the inclusions and host cells subsequently lyse there is a decrease, rather than an increase, in surface antigen. This suggests that the increase in host cell surface antigen during the earlier part of the reproductive cycle is associated with an increase in the number of intracellular chlamydiae. The passage of antigen to the surface of neighbouring cells and to other cells which do not seem to be in direct contact with one which is infected demonstrates that the presence of a chlamydial inclusion is not required for cell surface association of LPS. Therefore any disruption to host cell metabolism or membrane formation caused by the proliferation of chlamydiae and the formation of the inclusion membrane does not seem to be relevant to presence of cell-surface-associated antigen. Lastly, the antibodies used in this study do not appear to react with the glycolipid described by Stuart and colleagues (Stuart et al., 1991), as the cell-surface antigen which they describe could be visualized after methanol fixation. LPS, by contrast, is masked in the hydrated unfixed host cell and is extracted by solvent fixatives such as methanol or acetone. Infected host cells therefore need to be air-dried to expose the LPS epitopes recognized by monoclonal antibodies and polyclonal antisera. This drying procedure does not significantly distort the ultrastructure of the eukaryotic cell (except in a small minority of cases where the inclusions burst) or intracellular chlamydiae, neither does it disperse intra-inclusion chlamydial antigens stained by immunofluorescence with polyclonal antisera (Richmond \& Stirling, 1981). Drying does, however, prevent penetration of antibody into the host cell.

The source of the LPS associated with the host cell surface is probably the single membrane vesicles (outer membrane blebs) which are produced by replicating chlamydiae (Stirling \& Richmond, 1980). These vesicles, which contain genus antigen detectable by immuno-electron microscopy with polyclonal antiserum (Richmond \& Stirling, 1981), accumulate in large numbers within the inclusion (Richmond \& Stirling, 1980). Evidence is still required to show that they fuse with the inclusion membrane, and the mechanism by which antigen is released from there to the cell surface is not yet known. However, the absence of MOMP in association with the cell surface, and the close association of LPS on the host cell surface overlying the inclusion, suggest that a lipidbased diffusion mechanism is operative. LPS has been demonstrated in the vicinity of the surface membrane of McCoy cells by post-embedding immunochemical techniques (Hearn \& McNabb, 1991), although normal fixation methods do not reveal intracytoplasmic LPS.

The LPS that becomes associated with the infected host cell surface is transferred in detectable amounts to the surface of neighbouring uninfected cells so that LPS excreted by one mature inclusion can involve up to 50 neighbouring cells. This gives rise to the distinctive plaques of LPS-contaminated cells seen in infected, airdried cell cultures stained by immunofluorescence described here and in earlier work (Richmond \& Stirling, 1981; Karimi et al., 1989). The formation of these plaques is preceded by the appearance of LPS in patches on the surface of the inclusion-bearing cell and its adjoining neighbours. Our qualitative observations suggest that gradients in LPS concentration exist over the infected cell and its neighbours. The presence of a non-uniform distribution in the host cell membrane, which was observed more easily in elongated or well-spread cells, and its masking in the hydrated state suggest that movement in the plane of the cell membrane is constrained either by self-association or by association with components of the cell surface. The existence of LPS at the periphery of lamellipodia in isolated infected endometrial epithelial cells suggests that these cells, which are constantly changing their shape during the course of locomotion over the substratum, either internalize and redistribute some cell-surface-associated material or direct the LPS from the inclusion to newly forming host cell membrane.

Since cell monolayers were very thoroughly washed before drying, the development of plaques probably involved some form of direct host cell interaction. Close 
examination of the outer cells of the plaques strengthened this view, for antigen was only observed at cell edges where cell contact could occur. The precise nature of this interaction and the transfer mechanism have yet to be elucidated. Wilde and colleagues have suggested that the physical properties of the membrane change as a result of the association of LPS (Wilde et al., 1986; Karimi et al., 1989), although it is not clear whether this could promote cell-to-cell transfer. Physiological evidence of changes in membrane function in neighbouring LPS-contaminated but uninfected cells is now required before the pathological significance of cell surface associated LPS can be assessed.

Others have emphasized the lack of cell-mediated cytotoxicity to chlamydia-infected cells (Pavia \& Schachter, 1983; Qvigstad \& Hirschberg, 1984; Stagg et al., 1992). Our results suggest in addition that complement-mediated damage by antibody recognition of surface-associated LPS should not take place in living hydrated cells. It is therefore likely that in natural infections host cells bearing this antigen will escape immune surveillance while the organisms are replicating, thus making intracellular survival within the host organism more successful.

\section{ACKNOWLEDGEMENTS}

We thank Dr Mourad Seif for supplying endometrial tissue and Dr John Aplin for cultures of human amniotic epithelium. This work was supported by an MRC project grant.

\section{REFERENCES}

Aplin, J. D., Campbell, S. \& Allen, T. D. (1985). Human amnion extracellular matrix ultrastructure composition and deposition. $J$ Cell Sci 79, 119-136.

Bacon, E. J., Richmond, S. J., Wood, D. J., Stirling, P., Bevan, B. J. \& Chalmers, W. S. K. (1986). Serological detection of phage infection in Chlamydia psittaci recovered from ducks. I'et Rec 119, 618-620.

Baumann, M., Brade, L., Fasske, E. \& Brade, H. (1992). Staining of surface antigen of Chlamydia trachomatis $\mathrm{L}_{2}$ in tissue culture. Infect Immun 60, 4433-4438.

Campbell, S., Richmond, S. J., Haynes, P., Gump, D. W., Yates, P. \& Allen, T. D. (1988). An in vitro model of Chlamydia trachomatis infection in the regenerative phase of the human endometrial cycle. $J$ Gen Microbiol 134, 2077-2088.

Campbell, S., Richmond, S. J. \& Yates, P. (1989). The development of Chlamydia trachomatis inclusions within the host eukaryotic cell during interphase and mitosis. J Gen Microbiol 135, 1153-1165.

Campbell, S., Yates, P. S., Waters, F. \& Richmond, S. J. (1991). Purification of Chlamydia trachomatis by a simple and rapid filtration method. I Gen Microbiol 137, 1565-1569.

Dhir, S. P., Kenney, G. E. \& Grayson, J. T. (1971). Characterisation of the group antigen of Chlamydia trachomatis. Infect Immun 4, 725-730.

Dwyer, R. St. C., Treharne, J. D., Jones, B. R. \& Herring, J. (1972). Chlamydial infection. Results of microimmunofluorescence tests for the detection of type specific antibody in certain chlamydial infections. Br J Infect Dis 48, 452-458.

Francis, T. \& Magill, T. P. (1938). An unidentified virus producing acute meningitis and pneumonitis in experimental animals. $J$ Exp Med 68, 147-160.
Galanos, C., Luderitz, O. \& Westphal, O. (1969). A new method for the extraction of R lipopolysaccharides. Eur J Biochem 9, 245-249.

Hearn, S. A. \& McNabb, G. L. (1991). Immunoelectron microscope localisation of chlamydial lipopolysaccharide (LPS) in McCoy cells inoculated with Chlamydia trachomatis. J Histochem Cytochem 39, 1067-1075.

Howard, L., Orenstein, N. S. \& King, N. W. (1974). Purification on renografin density gradients of Chlamydia trachomatis grown in the yolk sac of eggs. Appl Microbiol 27, 102-106.

Igietseme, J. U. \& Rank, R. G. (1991). Susceptibility to reinfection after a primary chlamydial genital infection associated with a decrease of antigen-specific $\mathrm{T}$ cells in the genital tract. Infect Immun 59, 1346-1351.

Karimi, S. T., Schloemer, R. H. \& Wilde, C. E. (1989). Accumulation of chlamydial lipopolysaccharide antigen in the plasma membranes of infected cells. Infect Immun 57, 1780-1785.

Mearns, G., Richmond, S. J. \& Storey, C. C. (1988). Sensitive immune dot blot test for diagnosis of Chlamydia trachomatis. J Clin Microbiol 156, 1810-1813.

Morgan, H. R. \& Wiseman, R. W. (1946). Growth of psittacosis virus in roller tube tissue culture; use in a vaccine. I Infect Dis $\mathbf{7 9}$, 131-133.

Morrison, R. P. (1990). Immune responses to chlamydia are protective and pathogenic. In Proceedings of the 7 th International Symposium on Human Chlamydial Infections, pp. 163-172. Edited by W. R. Bowie, H. D. Caldwell, R. P. Jones, P. A. Mardh, G. L. Ridgway, J. Schachter, W. E. Stamm \& M. E. Ward. Cambridge: Cambridge University Press.

Murray, E. S. (1964). Guinea pig inclusion conjunctivitis virus. 1. Isolation and identification as a member of the psittacosislymphogranuloma-trachoma group. J Infect Dis 114, 1-12.

Pavia, C. S. \& Schachter, J. (1983). Failure to detect cell-mediated cytotoxicity against Chlamydia trachomatis-infected cells. Infect Immun 39, 1271-1274.

Qvigstad, E. \& Hirschberg, H. (1984). Lack of cell-mediated cytotoxicity towards Chlamydia trachomatis infected target cells in humans. Acta Pathol Microbiol Immunol Scand Sect C 92, 153-159.

Richmond, S. J. (1980). Chlamydial group antigen in McCoy cells infected with Chlamydia trachomatis and Chlamydia psittaci. FEMS Microbiol Lett 8, 47-50.

Richmond, S. J. \& Stirling, P. (1981). Localisation of chlamydial group antigen in McCoy cell monolayers infected with Chlamydia trachomatis or Chlamydia psittaci. Infect Immun 34, 561-570.

Richmond, S. J., Stirling, P. \& Ashley, C. R. (1982). Virus infecting the reticulate bodies of an avian strain of Chlamydia trachomatis. FEMS Microbiol Lett 14, 31-36.

Richmond, S. J., Storey, C. C. \& Lusher, M. (1990). Transmission of phage Chp1 within Chlamydia. In Proceedings of the 7 th International Symposium on Human Chlamydial Infections, pp. 153-165. Edited by W. R. Bowie, H. D. Caldwell, R. P. Jones, P. A. Mardh, G. L. Ridgway, J. Schachter, W. E. Stamm \& M. E. Ward. Cambridge: Cambridge University Press.

Sompolinsky, D. \& Richmond, S. J. (1974). Growth of Chlamydia trachomatis in McCoy cells treated with cytochalasin B. Appl Microbiol 28, 912-914.

Stagg, A. J., Elsley, W. A. J., Holland, M., Ward, M. E. \& Knight, S. C. (1992). Dendritic cells (DC) in the initiation of immune responses to chlamydia. In Proceedings of the European Society for Chlamydial Research, vol. 2, pp. 77-80. Edited by P.-A. Mardh, M. La Placa \& M. Ward. Uppsala: European Society for Chlamydial Research.

Stirling, P. \& Richmond, S. J. (1977). The developmental cycle of 
Chlamydia trachomatis in McCoy cells treated with cytochalasin B. $J$ Gen Microbiol 100, 31-42.

Stirling, P. \& Richmond, S. J. (1980). Production of outer membrane blebs during chlamydial replication. FEMS Microbiol Let: 9, 103-105.

Storey, C. C., Mearns, G. \& Richmond, S. J. (1987). Immune dot blot technique for diagnosing infection with Chlamydia trachomatis. Genitourin Med 63, 357-379.

Storey, C., Lusher, M., Yates, P. \& Richmond, S. (1993). Evidence for Chlamydiae pneumoniae of non-human origin. J Gen Microbiol 139, 2621-2626.

Strauss, J., Bednar, B. \& Sery, V. (1957). The incidence of ornithosis and salmonellosis in the black-headed gull. II. Isolation and identification of ornithosis virus in the gull and simultaneous detection of Salmonella typhimurium. Cesk Epidemiol 6, 231-239.

Stuart, E. S., Wyrick, P. B., Choong, J., Stoler, S. B. \& Macdonald, A. B. (1991). Examination of chlamydial glycolipid with monoclonal antibodies: cellular distribution and epitope binding. Immunology 74, 740-747.
Thornley, M. J., Zamze, S. E., Byrne, M. D., Lusher, M. \& Evans, R. T. (1985). Properties of monoclonal antibodies to the genus specific antigen of Chlamydia and their use for antigen detection by reverse passive haemagglutination. $J$ Gen Microbiol 131, 7-15.

Wang, S. P. \& Grayston, J. T. (1971). Classification of trachoma and related strains by microimmunofluorescence. In Trachoma and Related Disorders, pp. 305-321. Edited by R. L. Nichols. Amsterdam: Exerpta Medica.

Wilde, C. E., Karimi, S. T. \& Haak, R. A. (1986). Cell surface alterations during chlamydial infections. In Microbiology - 1986, pp. 96-98. Edited by P. F. Leive, J. A. Boventre, J. A. Morello, S. D. Silver \& H. C. Wu. Washington, DC: American Society for Microbiology.

Wills, J., Gruffydd-Jones, T. J., Richmond, S. \& Paul I. D. (1984). Isolation of Cblamydia psittaci from cases of conjunctivitis in a colony of cats. Vet Rec 114, 344-346.

Received 5 November 1993; revised 11 January 1994; accepted 18 March 1994. 